American Journal of Applied Sciences 5 (7): 805-810, 2008

ISSN 1546-9239

(C) 2008 Science Publications

\title{
A Control Strategy for Photovoltaic-Solid Polymer Electrolysis System Based on Surface Temperature of PV Panel
}

\author{
${ }^{1}$ Riza Muhida, ${ }^{1}$ Wahyudi, ${ }^{2}$ Rifki Muhida, ${ }^{3}$ Ahmad Unggul Priantoro \\ ${ }^{1}$ Department of Mechatronics Engineering \\ ${ }^{2}$ Department of Science in Engineering \\ ${ }^{3}$ Departement of Electrical and Computer Engineering \\ Faculty of Engineering. International Islamic University Malaysia \\ Jalan Gombak, 53100, Kuala Lumpur, Malaysia
}

\begin{abstract}
Processes to produce hydrogen from solar photovoltaic powered water electrolysis using solid polymer electrolysis are reported. An alternative control of maximum power point tracking method based on analysis of PV panel's surface Temperature for the PV-SPE system was designed and implemented. From this analysis an optimal voltage of PV can be obtained and was realized as a reference voltage of Dc-DC converter. By maintenance the output voltage of PV using the reference voltage control, the output PV can be optimized at its MPP operation. The MPPT performance and hydrogen production performance of this method have been evaluated and discussed based on the results of the experiment.
\end{abstract}

Keywords: Photovoltaic, hydrogen energy, Dc-dc converter, solid polymer electrolysis (SPE)

\section{INTRODUCTION}

Photovoltaic hydrogen energy system is one of the candidates for the energy alternatives to solve the increasing environmental and energy problems. PVsolid polymer electrolysis is one of the methods to produce hydrogen from solar photovoltaic powered water electrolysis. Solar photovoltaic powered water electrolysis is highly possible, since the solar energy and water are available on the large scale. PV-hydrogen energy system as one of method to reduce the global warming and substitute the fuel of fossil cell. Therefore, hydrogen produced by this system can be used to replace the usage of oil and natural gas for transportation, heating and power utilities.

Since the PV-hydrogen energy system is expensive to build, it should be operated at their maximum output power levels. The PV output fluctuates with solar irradiation level, ambient temperature and load current, then in designing the PV-SPE system the effect of these three factors must be Considered ${ }^{[1]}$.

In this study, an alternative control for maximum power point tracking method applied to the PV-SPE system is designed and is implemented. An alternative control of maximum power point tracking method based on analysis of PV panel's surface Temperature for the PV-SPE system was designed and implemented. From this analysis an optimal voltage of PV can be obtained and was realized as a reference voltage of DcDC converter. By maintenance the output voltage of PV using the reference voltage control, the output PV can be optimized at its MPP operation. The MPPT performance and hydrogen production performance of this method have been evaluated and discussed based on the results of the experiment.

\section{SOLID POLYMER ELECTROLYSIS}

The research and development of solid polymer electrolyte began when Wright found ion conductivity in a PEO-alkaline metal ion complex in $1975^{[1]}$. Because of the favorable power density, Solid Polymer Electrolysis is a candidate for high efficiency, pollution free and others their potential applications in batteries, fuel cells, sensors and other electrochemical devices. In this chapter, the electrical characteristics of Solid Polymer Electrolysis and the effects of the its electrical characteristics on the hydrogen production will be reported.

Corresponding Author: $\quad$ Riza Muhida, Department of Mechatronics Engineering, Faculty of Engineering. International Islamic University Malaysia, Jalan Gombak, 53100, Kuala Lumpur, Malaysia, Tel: +603-6196-4487, Fax: +603-6196-4433 
SPE characteristics: SPE water electrolysis is one of the ways of producing hydrogen with comparatively high level of efficiency and compact equipment. The SPE is composed of a membrane, cathode and anode as shown in Fig. $1^{[2,3]}$, and specification of a unit cell prototype of SPE for laboratory scale experiment described in Table 1.

The SPE electrolysis produces hydrogen by providing pure water to one side of polymer ion exchange film, which is put between anode and cathode. The electrochemical conversions at the anode and cathode of SPE are as follows:

$\mathrm{H}_{2} \mathrm{O} \rightarrow 2 \mathrm{H}^{+}+\frac{1}{2} \mathrm{O}_{2}+2 e^{-}$(Cathode process)

$2 \mathrm{H}^{+}+2 e^{-} \rightarrow \mathrm{H}_{2}$ (Anode process)

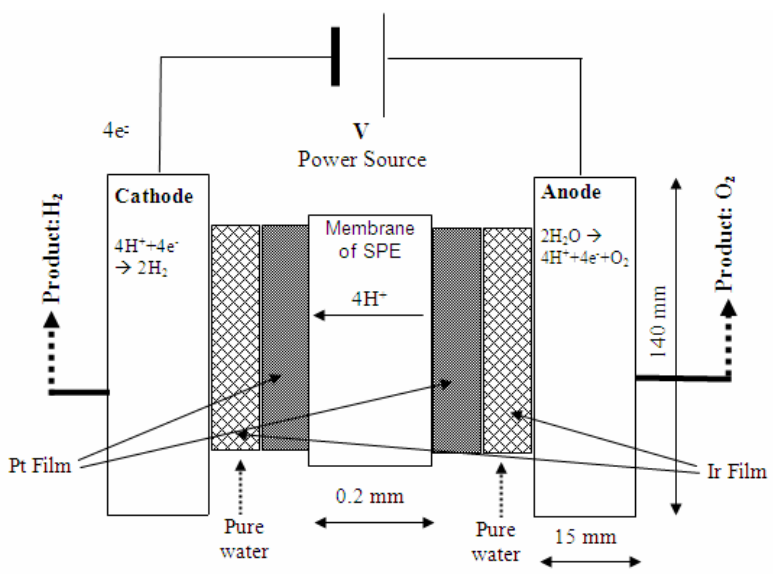

Fig. 1: Diagram of Solid Polymer Electrolysis

Table 1: specification of a unit cell prototype of SPE for laboratory scale experiment

\begin{tabular}{ll}
\hline Operating Temperature & $\mathrm{Up}$ to $90\left[{ }^{\circ} \mathrm{C}\right]$ \\
\hline Weight of main part & $1.7[\mathrm{Kg}]$ \\
Effective area & $50\left[\mathrm{~cm}^{2}\right]$ \\
$\begin{array}{l}\text { Maximum electrolyte } \\
\text { current }\end{array}$ & $50[\mathrm{~A}]$ \\
Electrolytic voltage & \\
Conversion efficiency & $2[\mathrm{~V}]$ \\
\hline
\end{tabular}

The V-I equation of a SPE cell is given by the following equation ${ }^{[3]}$.

$$
\mathrm{V}=\mathrm{V}_{\mathrm{o}}+\eta_{\mathrm{c}}+\eta_{\mathrm{a}}+\mathrm{IR}
$$

Where $\mathrm{V}$ is SPE cell voltage, $\mathrm{V}_{\mathrm{o}}$ is the theoretical dissociation voltage dependent on absolute temperature $\mathrm{T}$ [Kelvin] as shown below. ${ }^{[3]}$

$$
\mathrm{V}_{\mathrm{o}}=1.5-1.54 \mathrm{e}^{-3 * \mathrm{~T}}+9.5 \mathrm{e}^{-5^{*} \mathrm{~T} * \ln (\mathrm{T})}+9.8 \mathrm{e}^{-8^{*} \mathrm{~T}^{2}}
$$

$\eta_{c}$ as an excess voltage at the cathode side with the value varying from $0.05-1[\mathrm{~V}]$ at a cell current density of $1\left[\mathrm{~A} / \mathrm{cm}^{2}\right] . \quad \eta_{a}$ is an excess voltage at the anode side with a maximum value of $0.3[\mathrm{~V}]$ at cell current density $1\left[\mathrm{~A} / \mathrm{cm}^{2}\right] . \mathrm{R}$ is the electrical resistance of SPE and screen and that employed for the experiment has a value of $0.037[\Omega]$. I is the current that flows through the SPE.

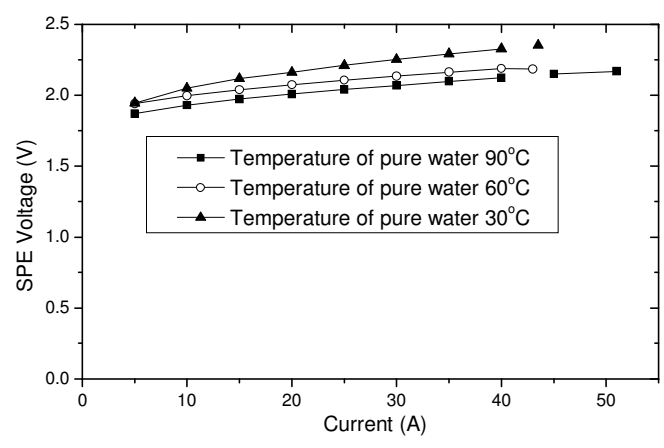

Fig. 2: V-I SPE Characteristics with feed water temperature as parameter. ${ }^{[2]}$

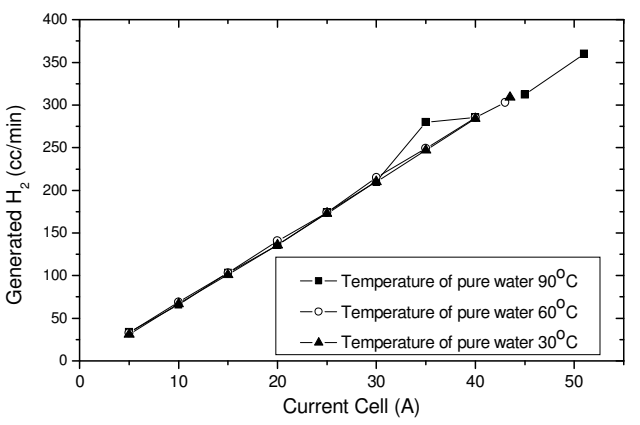

Fig. 3: Effect of current against the production rate of hydrogen. ${ }^{[2]}$

Because SPE produces hydrogen by extracting water as shown at Eq. (1), and the V-I output characteristics of SPE depends on water temperature as shown in Eq. (2) and (3). The experimental results illustrated in Fig. 2, with change the SPE cell temperature at 30,60 and $90^{\circ} \mathrm{C}$ we found the relation between electrolysis voltages was measured at various currents. 
As shown in Fig. 3. The relation between the production rate of hydrogen was measured at various current and under the SPE cell temperature at 30,60 and $90^{\circ} \mathrm{C}$. From the figure we can conclude that the production rate of hydrogen is proportional with the SPE current and the changing of the water temperature of SPE not so changes the production rate of hydrogen.

Effect of power input against the production rate of hydrogen: As shown in Fig. 4. The relation between the production rate of hydrogen was measured at various power input and under the SPE cell temperature from $30-60^{\circ} \mathrm{C}$. From the figure we can conclude that the production rate of hydrogen is proportional with the SPE power input.

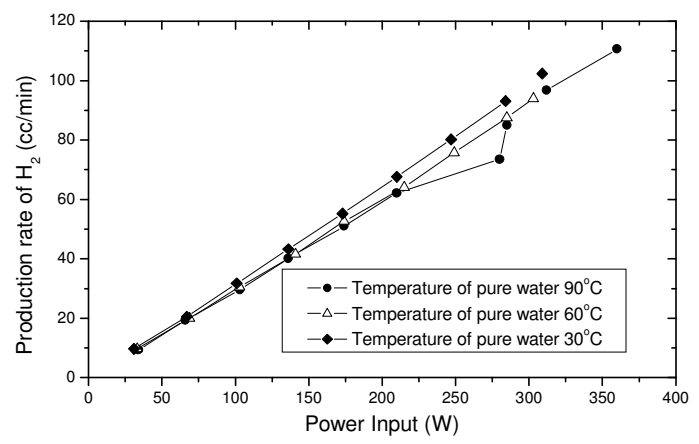

Fig. 4: Effect of power input against the production rate of hydrogen ${ }^{[2]}$

\section{PV-SPE MISMATCHING POINT}

The system designer aims to extract the maximum achievable electrical power output at all insolation levels to ensure efficiency of the system, especially considering the high cost associated with the PV panel and to overcome the mismatch between the PV panel and SPE.

An important design consideration is the match between the I-V characteristics of the PV panel and the SPE. If the SPE is connected directly to the PV panel it impossible to operate on the MPP of PV panel due to the mismatch.

Figure 5 shows a simplified mismatch point between PV and SPE. The measured performance of PV and SPE at insolation $0.2 \mathrm{~kW} / \mathrm{m}^{2}$ and surface PV temperature of $30{ }^{\circ} \mathrm{C}$ and the temperature of SPE water $60{ }^{\circ} \mathrm{C}$, the SPE cell voltage remain almost constant for all range of voltages on the PV panel. When PV and SPE are connected directly the mismatch between the PV panel and SPE occurs, that is the operating point (point A) is at a lower voltage than the maximum power voltage (point $\mathrm{P}$ ). This allows for voltage drops in the circuitry and the other diminutions in performance as mismatch losses. This loss can be calculated using the curve in Fig. 4. In this case, operating voltage will be $2.15 \mathrm{~V}$ and power output will be $4 \mathrm{~W}$ against the maximum power output of PV panel 7.8 W. The loss of available PV power output is $48 \%$.

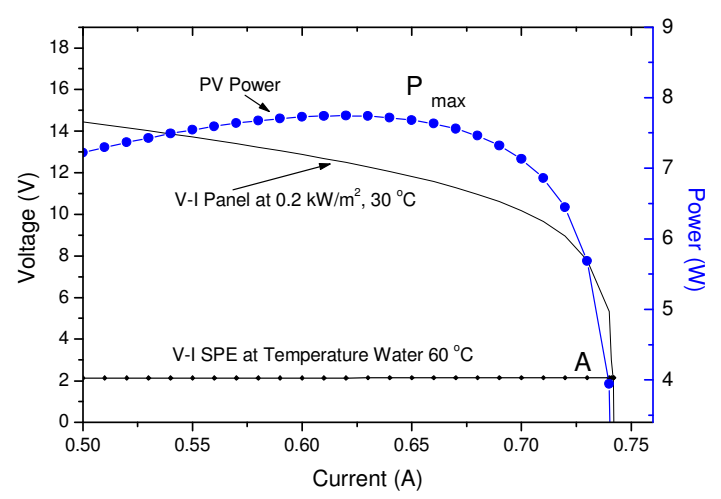

Fig.5: PV-SPE mismatching point

As mentioned above, without a matching point between PV panel and SPE cell, the system efficiency can fall to an extremely low value, which makes the system uneconomical. To overcome this two options are available:

The first include the careful selection of the SPE that matches the maximum power point of the PV panel as closely as possible. In this situation the voltage of the SPE cell can be incooperated into the PV panel. However this makes the installation of this special SPE difficult. In other obstacle, as indicated in the previous paper ${ }^{[4]}$, is the mismatch between the rated PV panel and actual power, which perhaps result from the lower insolation levels and higher cell temperature. This is because the environmental changes cause the maximum power point to fluctuate, making it difficult to obtain the matching value between the actual MPPT of the PV panel power and the SPE parameters.

Due to this fluctuation it is of great interest to use the maximum power-point tracking (MPPT), which is an electronics control device that continuously matches the output characteristic of the PV panel to the input characteristics of the SPE. As a result of this matching process, the PV panel is forced to deliver maximum power to the SPE at all times. 


\section{MPP USING REFERENCE VOLTAGE CONTROL TECHNIQUE}

The performance of PV-SPE system can be enhanced by tracking the maximum power point of the PV panel and then using a dc-dc converter to match the SPE voltage. During this process, the step down dc-dc converter is used to drive a low voltage load from a high voltage PV panel. For this converter the output (SPE) voltage is always lower than the input PV panel. The power flow from the PV panel to the SPE is controlled by means of the on/off duty cycle of the switch.

The characteristic equation for the $p-n$ junction subject to insulation are as follows: ${ }^{[5]}$

$$
J=J_{s}-J_{o}\{\exp [e V / k T]-1\}
$$

Where

$\mathrm{J}=$ current density flowing into load. $\left(\mathrm{A} / \mathrm{m}^{2}\right)$

$\mathrm{J}_{\mathrm{s}}=$ short-circuit current density. $\left(\mathrm{A} / \mathrm{m}^{2}\right)$

$\mathrm{J}_{\mathrm{o}}=$ dark (saturation) current density $\left(\mathrm{A} / \mathrm{m}^{2}\right)$

$\mathrm{e}=$ charge on electron $\left(1.6 * 10^{-19} \mathrm{C}\right)$

$\mathrm{V}=$ voltage across cell $(\mathrm{V})$

$\mathrm{k}=$ Boltzmann's constant $\left(1.38 * 10^{-23} \mathrm{~J} / \mathrm{K}\right)$

$\mathrm{T}=$ absolute temperature of device $\left({ }^{\circ} \mathrm{K}\right)$

The maximum voltage across the cell would be achieved under open-circuit condition, or $\mathrm{J}=0$, that is:

$$
V_{o c}=\left(\frac{k T}{e}\right) \ln \left(\frac{J_{s}}{J_{o}}+1\right)
$$

Where $\mathrm{V}_{\mathrm{oc}}=$ open circuit voltage of cell.

The output power of the cell is:

$$
P=J V=\left\{J_{s}-J_{o}\left[\exp \left(\frac{e V}{k T}\right)-1\right]\right\} V
$$

The maximum power point (MPP) is obtained by taking the derivative of $\mathrm{P}$ with respect to $\mathrm{V}$ and setting the result equal to zero. This yield an implicit equation for the cell voltage at maximum power:

$$
\exp \left[\frac{e V_{m p p}}{k T}\right]\left[1+\frac{e V_{m p p}}{k T}\right]=1+\frac{J_{s}}{J_{o}}
$$

From eq. (5) and (7) we have

$$
V_{O C}=\frac{k T}{e} \ln \left(\exp \left(\frac{e V_{m m p}}{k T}\right)\left(1+\frac{e V_{m m p}}{k T}\right)\right)
$$

Using Maclaurin series to reduce these equations, then we get an approaching equation

$$
V_{m p p}=\frac{1}{2} V_{O C}-4 \frac{k T}{e}
$$

If parameters of each value of $e$ and $k$ are substituted in eq. (9), then eq. (9) will be:

$$
V_{m p p}=\frac{1}{2} V_{O C}-3.44 * 10^{-4} * T
$$

From eq. (10) we can find an optimal voltage of PV based on value of surface temperature. And then the optimal voltage was realized as a reference voltage for DC-DC converter.

The prototype aforementioned MPP technique for PV-SPE System using reference voltage controller schema were built and tested. A module of PV panel is used in the system and as load is a SPE cell, Fig. 6 shows schematic diagram of this technique.

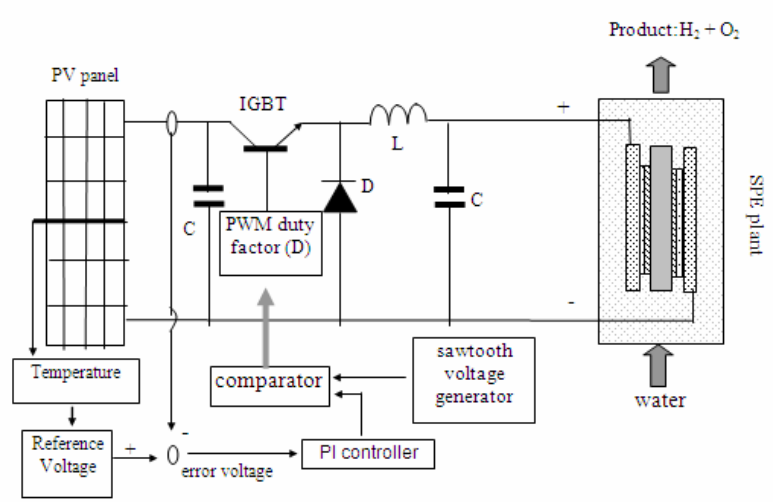

Fig. 6: Proposed total system

This method uses proportional integrator controller to control the duty factor of switch of pulse-width modulator (PWM) DC-DC Converter.

A description of the prototype is as follows:

a. A SPE plant with its specification as shown in Table 1.

b. A PV panel with its specification as shown in Table 2.

c. A proportional integrator controller consists of operational amplifier, capacitor and variable resistor.

d. The comparator and sawtooth voltage generator use IC TL494 as the PWM controller.

Table 2: Specification of a PV panel used in the experiment at insolation AM 1 and temperature $25^{\circ} \mathrm{C}$.

\begin{tabular}{ll}
\hline Type & C8P-4516 (Sanyo) \\
\hline Open circuit voltage $\left(\mathrm{V}_{\mathrm{OC}}\right)$ & $21[\mathrm{~V}]$ \\
Short circuit current $\left(\mathrm{I}_{\mathrm{SC}}\right)$ & $1.8[\mathrm{~A}]$ \\
Maximum power & $30[\mathrm{~W}]$ \\
Area & $0.4\left[\mathrm{~m}^{2}\right]$ \\
\hline
\end{tabular}


The principal work of this controller is that a reference voltage $\left(\mathrm{V}_{\text {ref }}\right)$ was generated by temperature sensor (thermocouple) and operational amplifier circuit. By use of PI controller an error voltage proportional to $\mathrm{V}_{\text {ref }}-\mathrm{V}_{\mathrm{PV} \text { output }}$ is resulted and then this error voltage is integrated and transmitted to the comparator. The transmitted signal is compared with sawtooth voltage. Therefore the result of comparator signal is used by IC TL 494 to produce a PWM signal to control the duty factor of switching frequency to drive MOSFET. By varying the duty factor of the switch, $\mathrm{I}_{\mathrm{PV}}$ and $\mathrm{V}_{\mathrm{PV}}$ can be controlled. If the error voltage is not zero, the signal to comparator will continuously increase and hence the duty factor will change in such a way to reduce the error voltage to become zero.

Since the voltage reference always changes depending on the surface temperature of PV as well as the output voltage of PV which fluctuates with solar radiation. As the consequence the controller will continue to track to get an equal value between the voltage reference and the output voltage of PV.

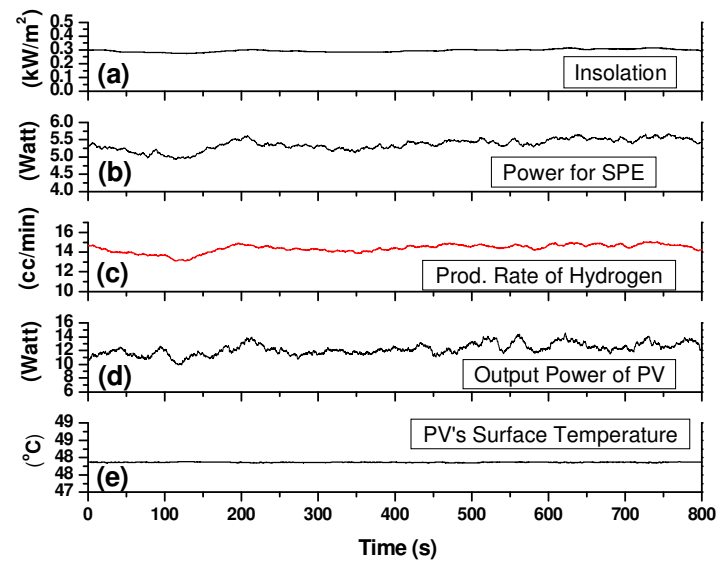

Fig. 7: Operation result of a prototype PV-SPE system

\section{RESULTS AND DISCUSSION}

Figure 7 shows a 13 minutes operation of the PVSPE system using MPP controller. A data acquisition system was used to measure the input voltage and current, cell temperature, insolation and the production rate of hydrogen. The experiment show that the power of the PV panel can successfully delivered the maximum power to the SPE at all times.

The comparison result of a experiment between using MPPT and without MPPT is illustrated in Fig. 8. We also did calculation to show numerical comparison as listed in Table 3.

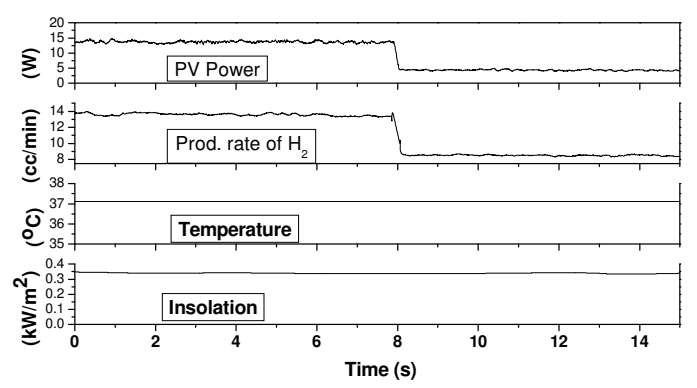

Fig. 8: Comparison result between using converter and without converter

Table 3: Comparison of the experimental result between using MPP and without MPP

\begin{tabular}{ll}
\hline Items & Results \\
\hline Average Insolation & $0.35 \mathrm{~kW} / \mathrm{m}^{2}$ \\
$\begin{array}{l}\text { Average Surface temperature of } \\
\text { PV panel }\end{array}$ & $35{ }^{\circ} \mathrm{C}$ \\
$\begin{array}{l}\text { PV Power using converter } \\
\text { PV Power without converter }\end{array}$ & $13.3 \mathrm{~W}$ \\
$\begin{array}{l}\text { Advantage Power using } \\
\text { Converter }\end{array}$ & $6.2 \mathrm{~W}$ \\
$\begin{array}{l}\text { Production Rate of } \mathrm{H}_{2} \text { using } \\
\text { converter }\end{array}$ & 13.5 \\
$\begin{array}{l}\text { Production rate of } \mathrm{H}_{2} \text { without } \\
\text { converter }\end{array}$ & 8.5 \\
$\begin{array}{l}\text { Advantage of Prod. of } \mathrm{H}_{2} \text { using } \\
\text { converter }\end{array}$ & $37 \%$ \\
\hline
\end{tabular}

Based on Table 3 shows that using MPP technique was successful for increasing more the output of the production rate of hydrogen.

\section{CONCLUSION}

Since the PV-hydrogen energy system is expensive to build it should be operated at the maximum output power levels. However, the output of a PV generating system is not systemically tracked and influenced by various factors such as solar insolation, solar cell's temperature and the connected load condition (mismatching point). Therefore, in designing the PVSPE system the effect of these three factors should be considered. However, to overcome the adverse effects of system and to operate the PV panel at maximum power point (MPP) every instant, a MPPT is essential. The production system of hydrogen using the maximum power Point Tracking based on PV's surface 
temperature has been proposed in this paper. The main conclusions reached in this study are as follows:

1. The proposed control methods based on the PV surface temperature method for PV-SPE system has been realized and tested.

2. The maximum power point tracking control scheme was successful for increasing more the output of the production rate of hydrogen.

\section{REFERENCES}

1. Soltermann O.E. and Da Silva E.P., 1988. Comparative study between the hysolar and a hypothetical international project in Brazil for hydrogen production and exportation (BHP) from photovoltaic energy and secondary hydroelectricity combined supply, Int. J. Hydrogen Energy 23 (9) (1988) 735-739.
2. K. Torigoe, 1999. Thermoelectric-hydrogen production system for $\mathrm{CO} 2$ recycle, Master Thesis, Osaka University, (In Japanese).

3. H. Takenaka, 1987. SPE electrolysis technology: Characteristics and Applications", GS News Technical Report, Japan Battery, Vol. 46, No. 1, June 1987. (In Japanese)

4. JHR Enslin and DB Snyman, 1992. Simplified feed-forward control of the maximum power point in PV installations, IEEE IECON RECORD, San Diego, pp. 548-553

5. M.A Green, 1982. Solar Cell operating principles, technology and system application, prentice-Hall Inc., Englewood Cliffs, NJ. 